\title{
Knowledge, Opinions, and Behaviors Regarding the Family Planning Methods among Married Men in Sanliurfa, Turkey
}

\author{
İzzettin EKINCI, Nurse ${ }^{1}$, Fatma KORUK, Assoc. Prof ${ }^{2 *}$
}

${ }^{1}$ Harran University Institue of Health Science, Sanliurfa, Turkey

${ }^{2}$ Harran University Faculty of Health Sciences, Nursing Department, Sanliurfa, Turkey

DOI: $\underline{10.36348 / \text { sjnhc.2019.v02i11.006 }}$

| Received: 21.11.2019 | Accepted: 28.11.2019 | Published: 30.11.2019

*Corresponding author: Fatma KORUK, Assoc. Prof

\section{Abstract}

Family planning services are important for the health of mothers and babies, Family planning services are important for the health of mothers and babies, preventing both unwanted pregnancies and superfecundity. Sanliurfa has the highest fertility rate in Turkey, and the rate of giving birth at very young and old ages and mother-baby deaths are also high there. Therefore, it is important to encourage access to and use of family planning services among men in Sanliurfa, which has a patriarchal societal structure. This study aimed to determine the knowledge, opinions, and behaviors regarding FP methods among married men living in Sanliurfa, Turkey. The sample of this cross-sectional study included 300 married men aged over 18. The study found that married men living in Sanliurfa had a high level of knowledge about family planning methods; however, their use of family planning methods was low. They also held the opinion that men should actively take part in the use of family planning methods. Language and social insurance were found to be the most important factors affecting men's use of family planning methods.

Keywords: Married men, family planning, modern methods, and traditional methods.

Copyright @ 2019: This is an open-access article distributed under the terms of the Creative Commons Attribution license which permits unrestricted use, distribution, and reproduction in any medium for non-commercial use (NonCommercial, or CC-BY-NC) provided the original author and source are credited.

\section{INTRADUCTION}

Family planning (FP) services are important for the health of mothers and babies, preventing both unwanted pregnancies and superfecundity, and thus play an important part in the improvement of health on the community level [1].

Various factors affect the use of FP methods. These include women's age, the education level of their husband, socio-economic status, social status, family type, society's socio-cultural structure, marriage age, age at first pregnancy, men's participation in FP, wanted miscarriages, unwanted pregnancies, religious beliefs, and delivery method [2]. Factors such as trust in the protective method, incorrect use and false knowledge of the protective method, individual/social characteristics, and similar factors also affect the use of FP methods [3]. Studies have reported that men's participation in and support for the use of FP methods are the most important factors affecting the use of FP methods $[2,4,5]$. Men often take part in deciding which FM method to use and direct women's decisions regarding their reproductive health. Studies have found that reproductive health programs for women become more effective when men participate $[4,5]$.
The data of the 2013 Turkey Population Health Research show that the general fertility rate in Turkey is 2.26 , and use of any kind of FP method is $73.5 \%$. The general fertility rate in southeastern Anatolia, where Sanliurfa is located, has since increased to 3.41 while use of FP methods has dropped to $59.7 \%$ [6]. However, Sanliurfa has the highest fertility rate at 4.13 , and high rates of giving birth at very young and old ages and mother-baby deaths, according to the Turkish Statistical Institute Birth Statistics for 2018 [7]. This indicates that access to and availability of FP services in Sanliurfa are a top priority. Encouraging men in Sanliurfa, which has a patriarchal societal structure, to participate in these services will be an effective way to improve access to and use of FP services.

This study aimed to determine the knowledge, opinions, and behaviors regarding FP methods among married men living in Sanliurfa.

\section{MATERIALS AND METHODS Setting and Sample}

This cross-sectional study was carried out between February and June 2019 in Sanliurfa, a city in 
southeastern Turkey. In a study conducted by the State Planning Organization, Sanliurfa was ranked 73rd out of 81 cities in terms of socioeconomic development [8].

The study was conducted in central counties of Sanliurfa which are Eyyübiye, Haliliye, and Karaköprü. Most of the men in the neighborhoods selected had a similar economic status and worked as government officers, workers, tradesmen, animal breeders, or agricultural workers. The literacy rate varied across neighborhoods. Most of the individuals living in the region speak Turkish or Kurdish.

The study population included 319,119 married men who lived in 28 different neighborhoods in the central counties of Sanliurfa based on the data of the Turkish Statistical Institute (TUIK) 2017 [9]. The sample was selected using the 30-set sampling technique advised by the World Health Organization, each set including ten participants, so that 300 men were included in the study[10]. Thirty streets were selected from a list of streets in the neighborhoods using the simple random method. The third home on the street was determined as the starting point and the research continued the right-hand side of the street until the number of participants reached ten.

\section{The Ethical Dimension of the Research}

The written permission of the Ethics Committee of Harran University and the verbal permission of participants were obtained for the research.

\section{Data Collection Tools}

The study data were collected via face-to-face interviews using a data collection form. The data collection form included 11 questions on sociodemographic characteristics (age, educational level, employment status of husband and wife, language(s) most commonly used at home, income level, health coverage, family type, duration of marriage), 12 questions on fertility and marriage (total number of pregnancies, number of living children, status of planned pregnancies, place of delivery, delivery mode, whether problems were encountered during delivery, sex of the baby, age of the baby, existence of health problems in the baby), and 25 questions on factors related to FP (FP method used, duration of use, FP methods known, where they got information, frequency of use, reasons for choosing the FP method used).

\section{Variables}

The dependent variable of the study was the status of using any kind of FP method (modern or traditional methods). The independent variables were socio-demographic characteristics, factors related to fertility, and FP.

\section{DATA ANALYSIS}

The study data were assessed using the Statistical Package for Social Sciences (SPSS) for Windows 16.0 program. The data were analyzed by percentage, means, standard deviation of the descriptive statistics, and Chi-squared and MannWhitney $U$ tests of univariate analysis. The study assessed the effect of the independent variables on the use of FP methods. The independent variable was categorized as those using a modern method (condom, intrauterine device, oral contraceptives, and spermicides) or a traditional method (withdrawal, vaginal lavage, and calendar method) for univariate analysis, excluding participants who did not use any FP method and those who were unfamiliar with any FP method. The results were assessed at $95.0 \%$ confidence interval and at a significance level of 0.05 .

\section{RESULTS}

The mean age of the men was $33.4 \pm 8.8$ years; $14.0 \%$ had not completed any level of education (literate) and $10.0 \%$ were unemployed; $53.05 \%$ earned less than their expenses and $27.0 \%$ did not have health coverage. Moreover, $45.0 \%$ smoked cigarettes and $10.3 \%$ had a chronic condition. The mean age of the participants' wives was $29.4 \pm 7.9$ years; $47.7 \%$ of wives had not completed any level of education (literate) and $85.3 \%$ were housewives. The mean duration of participants' marriage was $10.3 \pm 8.7$ years. The most frequently used languages in the home environment were Kurdish (37.7\%) and Arabic (35.5\%).

The women's mean age when they had their first child was $24.3 \pm 3.6$ years and they had had $8.5 \pm 3.7$ pregnancies on average. The mean number of abortions was 3.4 \pm 3.6 and the mean number of miscarriages was $1.9 \pm 0.9$. Most of the time, men decided to have a child $(49.0 \%)$ and $50.3 \%$ of them did not have a preference regarding the sex of the child. The most recent pregnancies of the majority of the women $(61.3 \%)$ were unplanned.

Of the men, 9.3\% were unfamiliar with any FP method and $65.3 \%$ had not obtained information on FP methods. Of the men who had obtained information on FP, $64.0 \%$ got information about the withdrawal method and $75.6 \%$ on the condom method. They mostly got this information from healthcare personnel (29.3\%) and social environment $(5.7 \%)$.

Half of the men $(50.3 \%)$ had not used any contraceptive method before, $31.0 \%$ had used a condom, and $19.4 \%$ had used the withdrawal method; $12.3 \%$ were of the opinion that these methods were harmful and $8.3 \%$ considered them as unhealthy. Moreover, $51.0 \%$ stated that men should use FP methods and $41.3 \%$ stated that men should actively take part in the use of FP methods. Of those men who had used an FP method before, $8.3 \%$ had experienced difficulties while using it. The most commonly 
experienced difficulties were "negative effects on sex" $(3.5 \%)$, "not preventing pregnancy" (1.7\%), and "being unable to afford it" (1.0\%).

More than half of the men $(55.0 \%)$ had not used any FP method at the time of data collection. Of those who had used FP methods, $70.5 \%$ had used a modern method and $29.5 \%$ had used a traditional method. The most frequently used modern FP methods were condom $(45.6 \%)$ and intrauterine device $(14.8 \%)$. The most frequently used traditional method was the withdrawal method (29.5\%). The reason most often given for choosing this specific method was its perceived high level of protection $(20.0 \%)$ (Table 1 ). The mean duration of use of FP methods currently used was 22.9 \pm 10.9 years (Table 2). The mean duration of use of previously used FP method was $3.8 \pm 4.2$ years (Table 2).

Of the men who were currently using an FP method, $15.3 \%$ had decided to use it on their own while $14.3 \%$ had decided with their wives; $41.7 \%$ were pleased with the FP method they were using, 91.7\% had not experienced any difficulties with the method, and $82.0 \%$ found the method they used beneficial. The participants accessed the methods they used mostly via pharmacies (17.0\%) and hospitals (10.0\%). Only 3.3\% of the men thought about changing the method they used.

The researcher analyzed various factors that can affect men's use of modern methods. Modern method usage levels among the men who most often spoke Turkish in the home and had social insurance were higher. Statistical assessments indicated that the intergroup difference regarding the spoken language and social insurance state was statistically significant $(p<0.05)$ (Table 3).

No differences were found between those who used modern methods and those who used traditional methods in terms of educational level $(p=0.24)$, profession $(p=0.06)$, income-expense level $(p=0.37)$, wife's educational level $(p=0.85)$, wife's employment status $(p=0.84)$, chronic conditions $(p=0.56)$, age $(p=0.07)$, wife's age $(p=0.06)$, age at marriage $(p=0.32)$, duration of marriage $(p=0.35)$, age at birth of first child $(p=0.62)$, or preference regarding child's sex $(p=0.99)$ $(p>0.05)$.

Table-1: Distribution of Men's Factors Related to Family Planning Methods Currently Used

\begin{tabular}{|l|c|c|}
\hline Characteristics & Number & \% \\
\hline Using a Family Planning Method & 135 & 45.0 \\
\hline Yes & 165 & 55.0 \\
\hline No & 105 & 70.5 \\
\hline Family Planning Method Used* & 68 & 45.6 \\
\hline Modern FP Method & 22 & 14.8 \\
\hline Condom & 15 & 10.1 \\
\hline Intrauterine Device & 44 & 29.5 \\
\hline Oral Contraceptives & 44 & 29.5 \\
\hline Traditional FP Method & & \\
\hline Withdrawal & 32 & 10.7 \\
\hline The Reason for Choosing a Particular FP Method & 60 & 20.0 \\
\hline Economic & 15 & 5.0 \\
\hline High Level of Protection & 10 & 3.3 \\
\hline Easy Use & 18 & 6.0 \\
\hline Doctor's Recommendation & 165 & 55.0 \\
\hline Economic and Protective & $\mathbf{3 0 0}$ & $\mathbf{1 0 0}$ \\
\hline Not Using an FP Method & & \\
\hline Total &
\end{tabular}

Table-2: Distribution of Men's and Women's Factors Related to the Duration of Use of a Family Planning Method

\begin{tabular}{|l|c|c|}
\hline Characteristics & Mean \pm SD & Median (Min-Max) \\
\hline Duration of Currently Used FP Method (Years) & $22.9 \pm 10.9$ & $31.0(2-31)$ \\
\hline Duration of Previously Used FP Method (Years) & $3.8 \pm 4.2$ & $2.0(1-21)$ \\
\hline
\end{tabular}

Table-3: Distribution of Men's Descriptive Features Regarding the Family Planning Method Used

\begin{tabular}{|l|c|c|c|c|c|c|}
\hline \multicolumn{7}{|c|}{ Method Used } \\
\hline & \multicolumn{2}{|c|}{ Modern } & \multicolumn{2}{|c|}{ Traditional } & & \\
\hline Characteristics & Number & \% & Number & \% & $\boldsymbol{X}^{2}$ & $\boldsymbol{p}$ \\
\hline Language Most Commonly Used in the Home & & & & & & \\
\hline Turkish & 51 & 81.0 & 12 & 19.0 & 8.052 & $\mathbf{0 . 0 1 8}$ \\
\hline Kurdish & 37 & 68.5 & 17 & 31.5 & & \\
\hline Arabic & 17 & 53.1 & 15 & 46.9 & & \\
\hline Social Insurance & & & & & & \\
\hline Yes & 95 & 74.8 & 32 & 25.2 & 7.761 & $\mathbf{0 . 0 0 5}$ \\
\hline No & 10 & 45.5 & 12 & 54.5 & & \\
\hline
\end{tabular}




\section{DISCUSSION}

Sociodemographic characteristics are one of the significant factors that affect the use and efficacy of FP services. This study found that $14.0 \%$ of the men in the sample had not graduated school but they were literate. This rate is quite low compared to average rate in Turkey. The TUIK 2018 data show that the rate of men who do not graduate school is $2.7 \%$. Similarly, the study reports that almost half of the wives in the sample had not graduated school but were literate. According to the TUIK 2018 data, the average rate of women who do not graduate school is $7.9 \%$ [11]. Considering that education is an important factor that affects access to healthcare services, individuals with a low level of education should be regarded as a disadvantaged group.

Almost half of the men had an income lower than their expenses and almost one quarter did not have social insurance. Individuals who had social insurance for healthcare expenses benefit from healthcare services, and thus from FP services, more.

Although the official language of Turkey is Turkish, the majority of the men in the study's sample mostly spoke Arabic or Kurdish in their homes. Language and cultural differences are important to determining the comprehensibility and usability of services. Compatibility with the local language and culture is a basis for the successful delivery of healthcare services. Therefore, paying attention to these factors will increase the effectiveness of services.

Almost all of the participants were unfamiliar with any FP method while $34.7 \%$ had obtained information on FP methods. Similarly, Kitiş et al. found that $86.6 \%$ of the men in their study knew about FP methods [12]. The Turkey Population and Health Research 2013 data indicate that almost all couples knew about FP methods and 99.5\% knew about a modern FP method [6]. Having knowledge on the FP methods affects their use [12,13].

Men's usage of an FP method was $45.0 \%$. Of those who used FP methods, $70.5 \%$ used a modern method, while $29.5 \%$ used a traditional method. The TNSA 2013 data show that $73.5 \%$ of men used an FP method, and among these, $64.5 \%$ used modern methods and $35.5 \%$ used traditional methods [6]. The usage level of any FP method in the present study was lower than the average in Turkey; however, the usage rate of modern methods was higher than the average in Turkey. This might be because couples have chosen effective methods to reduce the number of pregnancies and problems concerning pregnancy. The mean number of total pregnancies was $8.5 \pm 3.7$ and almost one third of the wives in the sample had a bad obstetric history (miscarriage, abortion, unplanned pregnancy). The mean number of abortions was 3.4 \pm 3.6 and the mean number of miscarriages was $1.9 \pm 0.9$.
The most commonly preferred FP method was the condom $(45.6 \%)$. The preference for condom use identified in this study is higher than in Ersin et al. [14] (33.0\% in Sanliurfa), Vural et al. [15] (35.2\% in Kocaeli), Özdemir et al. [16] (35.2\% in Ankara), and the national average in Turkey according to the TNSA 2013 data $(15.8 \%)$ [6]. These findings indicate a positive result, showing that men mostly take responsibility for using an FP method. The majority of the participants stated that men should use an FP method and should actively take part in using it. However, they also stated that men mainly decide which FP method to use and how many children their couple has, and that couples prefer male children. This might indicate that, just like other decisions, men are active in deciding to use condoms or which FP method to use due to the patriarchal social structure of Sanliurfa. Considering the sociodemographic characteristics of their wives, that men dominate decisions on women's fertility was an expected result. Women's status, traditional family type, and educational level put them in a subordinate position when deciding which FP method to use, as in many other situations [17].

The literature indicates that there are various factors affecting men's use of modern FP methods [1821]. This study has examined the effects of sociodemographic variables (age, educational level, employment status, etc.), fertility-related variables (number of children, age of women at pregnancy and number of pregnancies, obstetric history, etc.), and various variables including chronic diseases and preference of child's sex on the use of modern methods. The study did not identify factors that affect the use of modern methods other than the language commonly used in the home and social insurance variables. Language discrepancies may cause problems in the delivery of healthcare services. This study found that having social insurance positively affected the use of modern FP methods. Having social insurance is an important factor determining the availability of healthcare services and increases the usage rates of these services, including FP services. Akın et al. supports this hypothesis. They found that the rates of modern FP method usage among married men with social insurance were higher than those who did not have social insurance [21].

\section{CONCLUSION AND SUGGESTIONS}

This study has found that married men living in Sanliurfa had a high level of knowledge about FP methods; however, their use of FP methods was low. They were also of the opinion that men should actively take part in the use of FP methods. Language and social insurance were identified as the most important factors affecting men's use of FP methods. To increase men's use of FP methods, interventions should be planned in 
accordance with sociodemographic factors, and training and counseling regarding FP should definitely be provided to couples together.

\section{REFERENCES}

1. Dirican, R., \& Bilgen, N. (1992). Public Health. 11. Edition. Uludağ University, Bursa; 377-390.

2. Saka, G. Ertem, M. İçlin, E. (2001). Risk Factors in Pregnant Women Delivered in Diyarbakır Maternity Hospital. Journal of Perinatalogy, 9(2): 110-5.

3. Gözükara, F., Kabalcığlu, Ersin, F.F.(2015). Determination of Attitudes of Women in Family Planning in Şanlıurfa Province. Harran University Journal of Medicine, 1(12).

4. Gharaibeh, M. K., Oweis, A., Shakhatreh, F., \& Froelicher, E. S. (2011). Factors associated with contraceptive use among Jordanian Muslim women: implications for health and social policy. Journal of International Women's Studies, 12(3), 168-184.

5. Ceylan, S., Tekbaş, Ö.F. (2000). A Holistic Approach to Family Planning; Participation of Men. Journal of Health and Society, 10 (3): 16-21.

6. Hacettepe University Institute of Population Studies, Turkey Demographic and Health Survey (DHS).(2013). Ankara. Access 15 May 2019. The URL is: http://www.hips.hacettepe.edu.tr/tnsa2013/rapor/T NSA_2013_ana_rapor.pdf.

7. Turkey Statistical Institute, June 19, 2019 Birth Statistics 2018. Access URL: http://www.tuik.gov.tr/prehaberbultenleri.do?id=3 0696

8. Republic of Turkey Ministry of Development. Provinces and Regions Socio-Economics Development Ranking Research, 2011. URL:http://www.undp.org.tr/Gozlem3.aspx?Webp age no=3946.

9. Turk Stat, Turkey Statistical Institute, Sanliurfa 2018. June 20, 2019 URL: http://www.tuik.gov.tr/prehaberbultenleri.do?id=2 7588\# 2019.

10. Training for mid-level managers: the EPI coverage survey. Geneva: World Health Organization, 1991 (unpublished document) WHO/EPI/91.10; available from Vaccines and Biologicals, World Health Organization, 1211 Geneva 27, Switzerland.
11. Turk Stat (2018). Educational Statistics, Statistical Tables and Dynamic Inquiry, Distribution of Population by Completed Educational Institution. Access 20 June 2019 URL: http: //www.tuik.gov.tr/PreTablo.do? Alt_id = 1018 .

12. Kitiş, Y., Bilgili, N., Karacam, Z. (2004). Gülveren Opinions of Men Living in the Health Center Region on Family Planning and Participation in the Decision: Journal of Health and Society, 14(1): 56-66.

13. Depe, Y., Erenel, A.Ş. (2006). Men's views and behaviors regarding family planning. Cumhuriyet University School of Nursing Journal, 10(3): 2936.

14. Ersin, F., Gozukara, F., Simsek, Z., Kurcer, M.A. (2002). Kayahan M. Şanlıurfa Tilfindır Married Women between 15-49 Years in Health Center Region Family Use of Family Planning Method and Reasons for Quitting. Diyarbakır: 8th National Public Health Congress Book. (185-188).

15. Vural, B., Vural, F., Diker, J., \& Yücesoy, I. (1999). Factors affecting contraceptive use and behavior in Kocaeli, Turkey. Advances in contraception, 15(4), 325-336.

16. Özdemir, O., Ocaktan, E., Çalışkan, D., Özyurda, F.(2004). Ankara University Faculty of Medicine Department of Public Health Family Planning Unit Evaluation of Applications Between 19992002 Journal of Ankara University Faculty of Medicine, 57(4): 195-203.

17. Population and Family Planning. (1990). Determinants of Fertility/Contraceptive Methods. International Printing, Human Resource Development Foundation Publication, Ankara Demiroglu Printing, 58-62.

18. Depe, Y., Erenel, A.Ş. (2006). Men's views and behaviors regarding family planning. Cumhuriyet University Journal of School of Nursing, 10(3): 29-36.

19. Ceylan, S., Tekbaş, Ö.F.(2000). A Holistic Approach to Family Planning; Participation of Men. Journal of Health and Society, 10(3): 16-21.

20. Altay, B., Gönener, D. (2006). Knowing and using family planning methods of married men and affecting factors. Firat Medical Journal, 14(1): 5664.1

21. Akin, L., Nilufer, Özaydın, N. Leo, D. (2006). Affecting the Use of Family Planning Methods of Married Men Factors in Turkey. Gülhane Medical Journal, 48: 63-69. 